\title{
Environmental modulation of the proteomic profiles from closely phylogenetically related populations of the red seaweed Plocamium brasiliense
}

\author{
Gabriela Calegario ${ }^{1,2}$, Lucas Freitas ${ }^{3,4}$, Eidy Santos ${ }^{5}$, Bruno Silva ${ }^{1,2}$, Gabrielle Sousa ${ }^{1,6}$, Louisi Oliveira ${ }^{1,2}$,

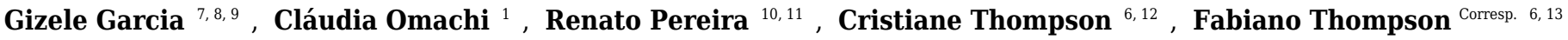 \\ 1 Institute of Biology, Federal University of Rio de Janeiro, Rio de Janeiro, Rio de Janeiro, Brazil \\ 2 SAGE-COPPE, Federal University of Rio de Janeiro, Rio de Janeiro, Rio de Janeiro, Brazil \\ 3 Department of Biochemistry, Federal University of Rio de Janeiro, Rio de Janeiro, Rio de Janeiro, Brazil \\ 4 Department of Genetics, Evolution, Microbiology and Immunology, State University of Campinas, Campinas, São Paulo, Brazil \\ 5 Unit of Biology, State University of the West Zone, Rio de Janeiro, Rio de Janeiro, Brazil \\ 6 SAGE-COPPE, Universidade Federal do Rio de Janeiro, Rio de Janeiro, Rio de Janeiro, Brazil \\ 7 Institute of Biology, Federal University of Rio de Janeiro, Rio de Janeiro, Brazil \\ 8 SAGE-COPPE, Federal University of Rio de Janeiro, Rio de Janeiro, Brazil \\ 9 Department of Undergraduate Education,, Federal University of Rio de Janeiro, Macaé, Brazil \\ 10 Department of Marine Biology, Fluminense Federal University, Niterói, Brazil \\ 11 Rio de Janeiro Botanical Garden, Rio de Janeiro, Brazil \\ 12 Institute of Biology, Universidade Federal do Rio de Janeiro, Rio de Janeiro, Rio de Janeiro, Brazil \\ 13 Marine Biology, Federal University of Rio de Janeiro-UFRJ \\ Corresponding Author: Fabiano Thompson \\ Email address: fabianothompson1@gmail.com
}

The genus Plocamium encompasses seaweeds that are widely distributed throughout the world's oceans, with Plocamium brasiliense found along the tropical and subtropical coasts of the Western Atlantic. This wide distribution can lead to structured populations due to environmental differences (e.g. light levels or temperature), restricted gene flow, and the presence of cryptic species. Abiotic variation can also affect gene expression, which consequently leads to differences in the seaweeds protein profile. This study aimed to analyze the genetic and proteomic profiles of $P$. brasiliense sampled in two geographically distinct sites on the coastline of Rio de Janeiro state, Brazil: Arraial do Cabo (P1) and Búzios (P2). The genetic profiles of macroalgal specimens from these two sites were indistinguishable as assessed by the markers UPA/23S, rbcL, and COI-5P; however, the protein profiles varied significantly between populations from the two sites. At both sites the ribulose-1,5-biphosphate carboxylase/oxygenase (RuBisCO) was the most abundant protein found in $P$. brasiliense specimens. The number of phycobiliproteins differed between both sites with the highest numbers being found at P1, possibly due to water depth. The differences in proteomic profiles of the two nearly identical populations of $P$. brasiliense suggest that environmental parameters such as light availability and 
desiccation might induce distinct protein expression, probably as a result of the phenotypic plasticity within this population of seaweed. 
1 Environmental modulation of the proteomic profiles from closely phylogenetically related

2 populations of the red seaweed Plocamium brasiliense

3

4 Gabriela Calegario ${ }^{1,2}$, Lucas Freitas ${ }^{3,4}$, Eidy Santos $^{5}$, Bruno Silva ${ }^{1,2}$, Louisi Oliveira ${ }^{1,2}$, Gizele

5 Garcia $^{1,2,6}$, Cláudia Omachi ${ }^{1}$, Renato Pereira ${ }^{7,8}$, Cristiane Thompson ${ }^{1,2 *}$, and Fabiano

6 Thompson ${ }^{1,2 *}$

7

$8{ }^{1}$ Institute of Biology, Federal University of Rio de Janeiro (UFRJ), Rio de Janeiro, Brazil

9 2SAGE-COPPE, Federal University of Rio de Janeiro (UFRJ), Rio de Janeiro, Brazil

$10{ }^{3}$ Departament of Biochemistry, Institute of Chemistry, Federal University of Rio de Janeiro

11 (UFRJ), Rio de Janeiro, Brazil

$12{ }^{4}$ Department of Genetics, Evolution, Microbiology and Immunology, Institute of Biology, State

13 University of Campinas (UNICAMP), Campinas, Brazil

$14{ }^{5}$ Unit of Biology, State University of the West Zone (UEZO), Rio de Janeiro, Brazil

$15{ }^{6}$ Department of Undergraduate Education, Federal University of Rio de Janeiro (UFRJ), Macaé,

16 Rio de Janeiro, Brazil

$17{ }^{7}$ Department of Marine Biology, Fluminense Federal University (UFF), Niterói, Rio de Janeiro, 18 Brazil

$19{ }^{8}$ Rio de Janeiro Botanical Garden (JBRJ), Rio de Janeiro, Brazil

20

$21 *$ Address for correspondence:

22 Fabiano L. Thompson

23 Federal University of Rio de Janeiro, 
24 Institute of Biology

25 Av. Carlos Chagas Filho, 373-CCS-IB-BLOCO A (ANEXO) A3-202

26 Cidade Universitária,

27 Rio de Janeiro, RJ

28 CEP: 21941-599,

29 Brazil

30 Phone: +55 21 3938-6567;

31 Email: fabianothompson1@gmail.com; Fax: +55 21 3938-6567; thompssoncristiane@gmail.com

32 Abbreviations: COI-5P, cytochrome c oxidase subunit; ML, maximum likelihood; m/z, mass-

33 to-charge ratio; RuBisCO, ribulose-1,5-biphosphate carboxylase/oxygenase; rbcL, RuBisCO

34 large subunit; UPA/23S, universal plastid amplicon, domain V of the plastid 23S rRNA gene;

35 MS, mass spectrometry; UPLC, ultra-performance liquid chromatography. 


\section{Abstract}

37 The genus Plocamium encompasses seaweeds that are widely distributed throughout the world's oceans, with Plocamium brasiliense found along the tropical and subtropical coasts of the

39 Western Atlantic. This wide distribution can lead to structured populations due to environmental differences (e.g. light levels or temperature), restricted gene flow, and the presence of cryptic species. Abiotic variation can also affect gene expression, which consequently leads to differences in the seaweeds protein profile. This study aimed to analyze the genetic and proteomic profiles of $P$. brasiliense sampled in two geographically distinct sites on the coastline

44 of Rio de Janeiro state, Brazil: Arraial do Cabo (P1) and Búzios (P2). The genetic profiles of macroalgal specimens from these two sites were indistinguishable as assessed by the markers $U P A / 23 S, r b c \mathrm{~L}$, and COI-5P; however, the protein profiles varied significantly between populations from the two sites. At both sites the ribulose-1,5-biphosphate carboxylase/oxygenase (RuBisCO) was the most abundant protein found in $P$. brasiliense specimens. The number of phycobiliproteins differed between both sites with the highest numbers being found at P1, possibly due to water depth. The differences in proteomic profiles of the two nearly identical

51 populations of $P$. brasiliense suggest that environmental parameters such as light availability and

52 desiccation might induce distinct protein expression, probably as a result of the phenotypic 53 plasticity within this population of seaweed. 


\section{Introduction}

Red seaweeds (Rhodophyta) are widely distributed around the world, inhabiting sites with different abiotic conditions, from polar to tropical regions (Harley et al. 2012, Guiry and Guiry 2016). The genus Plocamium (Plocamiales, Rhodophyta) comprises 40 heterogeneous species found in temperate to tropical oceans. This seaweed genus is gathering attention due its importance in the production of bioactive natural products, e.g. molecules with inhibitory properties against toxic effects of snake venoms (Claudino et al. 2014), anti-cancer (Alves et al. 2018), bone growth (Carson and Clarke 2018), anti-herbivore and herbicides(Pereira and CostaLotufo 2012, Pereira and Vasconcelos 2014). One example is the species Plocamium brasiliense, which occurs along the coasts of Brazil, Venezuela, Colombia, and the Caribbean Islands. This species is the only Plocamium found in Brazil and it ranges from the south of Espírito Santo state to Rio Grande do Sul, living in harsh environmental conditions such as desiccation stress and low temperatures $\left(<10^{\circ} \mathrm{C}\right)$. Morphology is highly variable among the 40 known species of the genus Plocamium, (Cremades et al. 2011).

The development of proteomics allows comparative studies of protein expression changes in response to changes in the environment (Tee et al. 2015, Getachew et al. 2016). Proteomic approaches are important tools to elucidate the mechanisms underlying the ability of seaweed species to tolerate a wide range of abiotic (Contreras-Porcia and López-Cristoffanini 2012) and biotic conditions (Getachew et al. 2014). Proteomics is an important tool to determine the protein repertoire of marine holobionts, including seaweeds, sponges, and corals (Garcia et al. 2016). Previous studies have shown that the protein profiles of the brown seaweed Saccharina japonica are affected by seasonal changes (Yotsukura et al. 2010). Similarly, protein profiles of the kelp Ecklonia cava differ considerably at higher temperatures, suggesting temperature stress-induced 
79 changes (Yotsukura et al. 2012). Epizootic colonization of seaweed may also lead to changes in

80 the biochemical composition of the seaweed host, which is reflected at the protein level

81 (Getachew et al. 2014). However, protein extraction presents challenges because the biochemical

82 and molecular characterization of seaweeds is limited compared to that of vascular plants and

83 animals (Contreras-Porcia and López-Cristoffanini 2012).

84 It is not clear how the genome of closely related populations of the same species respond 85 to different environmental conditions generating distinct proteome profiles. The wide 86 geographical distribution of $P$. brasiliense indicates a high phenotypic plasticity, which may be 87 explained by variations at the transcriptomic (de Oliveira et al. 2015) and probably proteomic 88 levels. In the present study we tested two assumptions: populations of $P$. brasiliense that inhabit 89 different geographic locations may be nearly identical genetically (first assumption), and the proteomes of these populations may differ in response to the environmental conditions (second

91 assumption). We aimed to understand how variable abiotic conditions influence the proteome of 92 P. brasiliense by analyzing protein expression profiles and the following molecular markers: 93 universal plastid amplicon, domain $\mathrm{V}$ of the plastid 23S rRNA gene $(U P A / 23 S)$, ribulose-1,594 biphosphate carboxylase/oxygenase (RuBisCO) large subunit $(r b c \mathrm{~L})$, and cytochrome c oxidase subunit I (COI-5P). In addition, there were not previous studies on proteomics of this seaweed.

2 Material and Methods

2.1 Study area and sampling 
101 August 2013 at Forno Beach (2245'41’S, 4152’32’W), located in Armação de Búzios (P2).

102 The two sampling locations are approximately $30 \mathrm{~km}$ apart.

103 Cabo Frio Island is located within a marine protected area (MPA) administered by

104 Brazilian Navy. This site is considered the major site of upwelling on the coast of Rio de Janeiro,

105 and the seawater temperature averages approximately $14^{\circ} \mathrm{C}$ but can be as low as $11.8{ }^{\circ} \mathrm{C}$

106 (Guenther et al. 2008). Seaweeds at the Arraial do Cabo site were collected by SCUBA diving.

107 The seaweed specimens were frozen in liquid nitrogen. Forno Beach is indirectly influenced by

108 upwelling and is one of the most ecologically preserved regions in the state, with a rocky shore

109 on both sides and a small $(150 \mathrm{~m})$ stretch of sand (Yoneshigue 1985). The seawater temperature

110 is normally approximately $18^{\circ} \mathrm{C}$ (Tâmega and Figueiredo 2005). P. brasiliense specimens were

111 collected at the Búzios site by free diving. These sites were chosen due (1) the morphological

112 differences between specimens from both sites, where Búzios had smaller individuals while

113 Arraial had bigger individuals and (2) environmental differences due upwelling, with Búzios

114 experiencing less influence of this event while Arraial is located directly under the influence of

115 upwelling. Seawater temperature was measured in situ, while chlorophyll a concentration was

116 obtained by satellite data analyzes (MODIS aqua; A20121772013272). Chlorophyll a values

117 were obtained every 8 days, from 26 June 2012 till 27 September 2013.

118

119

2.2 DNA extraction, PCR, and sequencing

120

We collected ten specimens per site and the total DNA was extracted from the algal

121 tissue using DNeasy ${ }^{\circledR}$ Plant Mini Kit (QIAGEN, Germantown, MD). We purified the DNA with

122 PowerClean ${ }^{\circledR}$ DNA Cleanup Kit (MO BIO, Carlsbad, CA). PCR was performed using the

123 Veriti ${ }^{\circledR}$ thermal cycler (Applied Biosystems, Foster City, CA) and the primers UPA/23S 
124 (Sherwood and Presting 2007), rbcL (Lin et al. 2001), and COI-5P (Saunders and Lehmkuhl

125 2005) using the amplification conditions described by these authors. These primers were chosen

126 since they showed good efficiency in distinguish algae populations when used in previously

127 population genetics of marine algae (Lin et al. 2001, Saunders and Lehmkuhl 2005, Sherwood 128 and Presting 2007). Sherwood et al. (2010) showed that UPA/23S and COI-5P are useful 129 markers for algal biodiversity surveys, while other studies demonstrate that rbcL is also a reliable 130 molecular marker (Yang et al. 2008, Tan et al. 2018).

PCR products were purified using USB ${ }^{\circledR}$ ExoSAP-IT ${ }^{\circ}$ PCR Product Cleanup

132 (Affymetrix, Santa Clara, CA) and then sequenced using an ABI 3500 automated sequencer

133 (Applied Biosystems), the same primers used for PCR reactions, and the ABI PRISM BigDye

134 terminator v3.1 Cycle Sequencing Kit (Applied Biosystems). The sequences were assembled 135 using CodonCode Aligner (CodonCode Corp., Centerville, MA).

136

1372.3 Phylogenetic analysis

138 Publicly available sequences for UPA/23S, $r b c \mathrm{~L}$, and COI-5P from Plocamium spp.,

139 Laurencia dendroidea and L. majuscule (closest species with sequence available) were

140 downloaded from GenBank (Benson et al. 2017). The total number of sequences used was 234,

14136 of which were obtained in this study (Table S1). Sequences for each gene were aligned 142 separately using the MUSCLE algorithm (Edgar 2004) on SeaView4 (Gouy et al. 2010) and 143 edited manually with MEGA7 software (Kumar et al. 2016).

144 To determine the potential species to be tested, we first reconstructed the topology of the 145 COI-5P Plocamium genus using the maximum likelihood (ML) approach in RAxML v. 8.1.17 146 (Stamatakis 2014) with a GTR $+\Gamma$ substitution model and 1,000 bootstrap replicates. We then 
147 selected lineages with more than five specimens. Using this new dataset (143 sequences), we

148 generated another ML tree using RAxML with the same parameters. For the multilocus dataset,

149 we reconstructed the ML tree using RAxML and the same parameters. Further, we calculated the

150 genetic differentiation between both populations using Nei’s $\mathrm{G}_{\mathrm{ST}}$ (Nei 1973).

1512.4 Protein extraction and separation

152 We selected six specimens of P. brasiliense collected in two closely related sites with

153 distinct environmental conditions (P1 and P2, three specimens from each site) for protein

154 extraction, SDS-PAGE, and identification. These procedures were carried out in two independent

155 experiments (i.e., two replicates each) following a modified protocol (Garcia et al. 2016). The

156 seaweed tissues were ground in liquid nitrogen using a mortar and pestle, and approximately 200

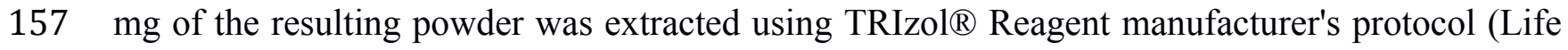

158 Technologies, Carlsbad, CA). After the final ethanol wash, purified proteins were dissolved in

159 resuspension buffer (7 $\mathrm{M}$ urea $2 \mathrm{M}$ thiourea, 4\% CHAPs, 40mM Tris). Quantification was

160 performed using the 2-D Quant kit (GE Healthcare, Little Chalfont, UK). We obtained protein

161 concentrations of about $2 \mathrm{mg} / \mathrm{mL}$ from $200 \mathrm{mg}$ of seaweed. After quantification, proteins were

162 fractionated by SDS-PAGE using a Mini-PROTEAN® Tetra handcast system (Bio-Rad

163 Laboratories, Hercules, CA). Protein samples (40 $\mu \mathrm{g})$ were mixed with resuspension buffer with

$1640.01 \%$ of bromophenolblue before loading onto gels. After electrophoresis, gels were stained

165 with Coomassie brilliant blue R-250 (GE-Amersham Biosciences, Little Chalfont, UK). Whole

166 lanes of the gels were sliced in bands, and proteins were digested with trypsin, as described

167 previously (Laemmli 1970, Coelho et al. 2004).

168

1692.5 Mass spectrometry and data analysis 
170 The resulting peptides from trypsin digestion were extracted from gel slices and analyzed

171 by LC-MS/MSin a Q-TOF quadrupole/orthogonal acceleration time-of-flight spectrometer

172 (Micromass) coupled to a Waters ${ }^{\circledR}$ nano-ultra performance liquid chromatography system

173 (UPLC) (Waters Corp., Manchester, UK), as described in Garcia et al. (2016). Tryptic peptides

174 were desalted and separated on Waters Opti-Pak C18 trap column and the C18 NanoEase 150

$175 \mathrm{~mm} \times 75 \mu \mathrm{m}$ column, in the nanoACQUITY UPLC® $1 \mathrm{D}$ chromatography system (Waters,

176 Milford, MA). Instrument control and data acquisition were conducted by the MassLynx data

177 system (Version 4.0, Waters) to perform the Data-dependent MS/MS acquisitions (DDA). The

178 exact mass of each signal from the total ion current chromatogram was determined automatically

179 using the Q-TofLockSpray ${ }^{\mathrm{TM}}$ (Waters, Milford, MA).

180 All data were processed using ProteinLynx Global server (version 2.5, Waters), by using

181 the lock spray reference ion to automatically correct the $\mathrm{m} / \mathrm{z}$ scale on MS data. Data of each

182 protein mixture obtained from gel slices were converted to peak list files (.pkl) by ProteinLynx

183 software. Protein identification was performed using MS/MS Ion Search at Mascot Server

184 (http://www.matrixscience.com/search_form_select.html; Matrix Science, London, UK) using

185 NCBI-nr database. Mascot search parameters included one missed cleavage, cysteine

186 carbamidomethylation, and methionine oxidation as fixed modifications, and a fragment mass

187 tolerance of $0.3 \mathrm{Da}$. The raw Mascot server results were screened to recognition of the correct

188 protein assignments. We considered real identifications, protein hits with Mowse scores higher

189 than 62 (the threshold score for protein identification) with at least two distinct peptides (with at

190 least 13 amino acid residues each) with reliable matches on protein sequence. Reliable matches

191 (indicated as bold red matches by the Mascot Server) were characterized by a peptide score 
192 number higher than the threshold for each run, with an expect value (P value) below $0.05(<5 \%$ 193 chance of being false).

194 Bioinformatics tools developed for protein identification are focused on single (model) 195 organisms, and the identification of tryptic peptides is still laborious and time consuming. 196 Studies focused on complex multispecies systems such as Plocamium holobionts demand the use 197 of large sequence databases. Moreover, the often-limited amount of available data (genomes and 198 transcriptomes) for this holobionts another important obstacle in metaproteomic studies and may 199 lead to peptide misidentification.

200 To test for potential false identification, a decoy database analysis was included using the 201 automatic decoy search in the Mascot Search Server (Matrix Science), with at least two distinct 202 peptide (>13 amino acid residues each) with reliable matches on protein sequence were one of 203 the minimal thresholds to identify a protein. Reliable matches (indicated as bold red matches by 204 the Mascot Server) were characterized by a peptide score number higher than the threshold for 205 each run, with an expect value (P value) below $0.05(<5 \%$ chance of being false). A match is the 206 highest scoring match to a particular query listed under the highest scoring protein containing 207 that match. This means that protein hits with many peptide matches that are recognized as 208 matches are the most likely correct assignments. Therefore our proteome analyzes were properly 209 represented in this study.

210 The automatic decoy database search performed by the Mascot server was used to 211 determine the false discovery rate (FDR). Functional contribution to seaweed proteomes were 212 assessed by grouping polypeptides that encompasses the same protein. Taxonomic categories of 213 each polypeptide type were inferred according to the Universal Protein Knowledgebase 214 (UniProt) (http://www.uniprot.org/uniprot/) classification. Taxonomic contributions were 
215 evaluated by clustering proteins from the same taxa. The relative contribution of each

216 protein/taxon was calculated based on the percentage number related to the total identified in

217 each condition. Then ANOVA test was applied to determine which proteins were significantly

218 more abundant at determined site $(\mathrm{p}<0.05)$ using R v. 3.3.3 (R Core Team 2017).

\section{Results}

223

The Plocamium populations studied here were obtained from two locations with different

224 environmental conditions. Seawater temperature was lower in $\mathrm{P} 1\left(13^{\circ} \mathrm{C}\right)$ than in $\mathrm{P} 2\left(23^{\circ} \mathrm{C}\right)$, while 225 chlorophyll a concentration was higher in P2 (Mean: $1.15 \mathrm{mg} / \mathrm{m}^{-3}$; Standard deviation: $1.91 \mathrm{mg} / \mathrm{m}^{-}$ 226 3; $\mathrm{N}=30$ ) than in P1 (Mean: $0.81 \mathrm{mg} / \mathrm{m}^{-3}$; Standard deviation: $\left.1.80 \mathrm{mg} / \mathrm{m}^{-3} ; \mathrm{N}=49\right)(\mathrm{p}$-value $=$ 2270.0004653, T-Test).

\subsection{COI-5P dataset}

To obtain an overview of the relationships within Plocamium we used the COI-5P gene

231 because of the large number of sequences available. The dataset consisted of 189 individuals and 232656 bp. Our ML tree consisted of 29 groups (Fig. 1) containing at least two individuals with high 233 bootstrap support values ( $>97$; Plocamium_sp_Aus_2 was the only exception, with a bootstrap 234 support value of 87). The relationships between groups and internal nodes of the tree did not 235 have good bootstrap support values, and four individuals from different species ( $P$. angustum, $P$. 236 cartilagineum, $P$. pacificum, and $P$. oregonum) did not cluster with any group. The species 237 sequenced in this work, $P$. brasiliense, which was sampled from two different sites, clustered 
238 into a single group, which was considered a sister lineage of a clade formed by $P$. suhrii and $P$.

239 raphelisianum.

240

2413.2 Multilocus dataset

242 Using a dataset with three genes (COI-5P, UPA/23S, and $r b c \mathrm{~L})$ we reconstructed a 243 concatenated ML tree with relationships between five species, where data of an individual was 244 available for two or more genes (Fig. 2), allowing one gene to be missed in the final nucleotide 245 matrix. This concatenated matrix consisted of 28 individuals and 1,073 bp. All species with more 246 than one individual analyzed had their monophyletic status inferred with high bootstrap support 247 value ( $>98)$. The sister lineage of $P$. brasiliense was inferred as $P$. telfairiae, and the low $\mathrm{G}_{\mathrm{ST}}$ 248 (0.09) coupled with our concatenated analysis indicated lack of structure between populations at 249 P1 and P2, rejecting the alternative hypothesis (structured populations), thereby supporting the 250 first assumption: individuals sampled in sites with different abiotic conditions do not form 251 structured populations.

252

253 3.3 Proteomic profile

The proteomes of six Plocamium brasiliense specimens (3 from Búzios and 3 from 255 Arraial do Cabo) were extracted and visualized by SDS-PAGE. A total of 132 SDS-PAGE slices 256 of protein bands were obtained (6 biological specimens, 2 technical replicates for each specimen, 257 Tables S2 and S3). Based on interpretation of Mascot searches against the NCBInr database, 258 2,791 polypeptides were identified from different taxa, encompassing 27 proteins. Average 259 values of the false discovery rate (FDR) were about $1 \%$ varying from $0 \%$ to $7 \%$. Of the total 260 specific proteins identified in holobionts $P$. brasiliense specimens collected from P1, 79.3\% were 
261 annotated as belonging to Rhodophyta, followed by those belonging to Embryophyta (4.1\%),

262 Cyanobacteria (3.3\%), Chordata and Mollusca (1.9\% each), and Arthropoda and Chlorophyta

263 (1.4\% each). Within Rhodophyta, 35.5\% of the identified proteins matched those of the genus

264 Plocamium or the genera Palmaria and Chondrus, species phylogenetically close to $P$.

265 brasiliense.

266 Of the total proteins identified in P. brasiliense specimens collected from P2, 82.2\% were

267 related to proteins annotated as belonging to Rhodophyta, followed by proteins belonging to

268 Cyanobacteria and Embryophyta (6.2\% each). Within Rhodophyta, $47.0 \%$ of the identified

269 proteins matched those of the genus Plocamium or the genera Chondrus and Gracilaria, species

270 phylogenetically close to $P$. brasiliense.

271 In the protein profiles of $P$. brasiliense specimens collected at P1 and P2, more than 20

272 bands were detected in each gel (each with 3 different biological replicates). From the 27

273 proteins five and four were significantly more abundant in P1 and P2, respectively (Table 1).

274 Within the energy metabolism biomolecule category, the abundance of the RuBisCO was similar

275 in both populations, while phycobiliproteins, especially phycocyanin, were significantly more

276 abundant in the $\mathrm{P} 1$ population than in the $\mathrm{P} 2$ population (Table 1).

277 Among photosynthesis-related proteins, ATP synthase, which participate in ATP

278 synthesis in the chloroplast, were detected in both populations of $P$. brasiliense but it was

279 significantly more abundant in P1. Taken together, our findings indicate that P. brasiliense

280 populations at P1 and P2 are non-structured populations; however, the behaviors of individuals

281 are influenced by their abiotic environment, as indicated by the differential protein profiles in the

282 two populations.

283 


\section{Discussion}

285 4.1 P. brasiliense populations from Búzios and Arraial have identical genetic profiles

286

Analysis of the phylogenetic markers (UPA/23S, $r b c \mathrm{~L}$, and COI-5P) in the two

287 populations evaluated in this study demonstrate that they belong to the $P$. brasiliense species.

288 The small $\mathrm{G}_{\mathrm{ST}}$ value (0.09) estimated between both populations in this study confirm our first

289 assumption, that despite being collected from geographically distinct sites, the populations are

290 indistinguishable. This finding is consistent with other studies evaluating Rhodophyta species.

291 For example, Gigartina skottsbergii populations collected at sites up to $45 \mathrm{~km}$ apart were shown

292 to be genetically homogeneous (Faugeron et al. 2004). Similarly, only a small genetic distance

293 was observed between closely related individuals of distinct populations of the red alga Gelidium

294 canariense separated by 0.5 to $21 \mathrm{~km}$, with a positive correlation between geographic and 295 genetic distances (Bouza et al. 2006).

296 Seaweeds are considered poor dispersers, because spores generally survive for only few 297 days (Santelices 1990). Indirect estimates indicate a low gene flow for seaweed species (Wright 298 et al. 2000), and suggest that short dispersal distances are significant in species differentiation 299 (Tatarenkov et al. 2007). However, despite the presumed poor dispersal of spores, the survival of $300 P$. brasiliense spores may be a factor in the unstructured populations of $P$. brasiliense, even at a 301 distance of approximately $30 \mathrm{~km}$. Corroborating the spore dispersion in long distances by red 302 algae, recently $\mathrm{Hu}$ et al. (2018) estimated a $\mathrm{G}_{\mathrm{ST}}$ smaller than 0.1 for Gracilariopsis 303 lemaneiformis populations distant by more than $200 \mathrm{~km}$.

304

3054.2 Environmental modulation of proteomic plasticity in Plocamium 
In this study, we aimed to analyze the $P$. brasiliense proteomes to disclose its modulation

307

308

309

310

311

in response to abiotic conditions. In addition to seaweed proteome, this study also focused on complex multispecies systems associated to $P$. brasiliense, that demand the use of large sequence databases. We used a combination of Trizol extraction and 1D electrophoresis for protein isolation and separation, which yields protein extracts of high quality and a less laborious and faster methodology for a general description of the seaweed proteomic pattern.

The seaweed $P$. brasiliense is an autotrophic alga, which means that it obtains energy through photosynthesis. The major photosynthesis-related protein found in P. brasiliense specimens was RuBisCO, which was the most abundant protein in both sites, while the second most abundant group were phycobiliproteins. Thus, accumulation of these pigments may help harvest light.

RuBisCO is a bifunctional enzyme that is involved in both carbon dioxide fixation and oxygenation (Wong et al. 2006), creating a metabolic pathway in which photosynthesis and photorespiration compete (Raines 2011). Further, the charge distribution on the active site of the RuBisCO, mainly the large chain may facilitate carbon uptake, enhancing survival and growth under stress conditions. For example, energy demand by Plocamium maybe higher in P2 due to the lower depth that may include periods of desiccation or nutrient-enrichment of seawater, as indicated by the higher chlorophyll a contents in the water of P2 observed here. As desiccation stress demands increased ATP, higher levels of chlorophyll proteins are needed to increase $\mathrm{CO}_{2}$ fixation by RuBisCO (Tee et al. 2015).

The presence of heat shock protein 70 (HSP70) in both populations of Plocamium also suggest possible environmental stress responses, or simply responses related with housekeeping roles in cells (e.g. protein folding, assembly, translocation and degradation) (Hartl 1996, Gerloff- 
329 Elias et al. 2006). Other stress-related proteins, like vanadium-dependent haloperoxidases, were 330 not found in our study.

331 Altogether phycobiliproteins were more abundant at P1, where the most abundant 332 phycobiliprotein was phycoerythrin $(27.36 \%)$, a possible response of the seaweed to higher 333 depth. In Rhodophyta and Cyanobacteria, phycobiliproteins (antenna complex) are always 334 associated with the photosynthetic apparatus (Lemasson et al. 1973, Sinha and Häder 2003). 335 These proteins are the major photosynthetic accessory pigments that absorb and transfer sunlight 336 to chlorophyll a (Bryant 1982). The number of phycobiliproteins detected in this study is 337 consistent with results of previous studies, which showed that light wavelength and water 338 temperature, both of which increase photosynthetic efficiency, directly affect the composition of 339 phycobiliproteins (Govindjee and Braun 1974).

340 Phycobiliproteins are classified into three major groups according to their absorption 341 spectrum: phycoerythrins $(540-570 \mathrm{~nm})$, phycocyanins $(610-620 \mathrm{~nm})$, and allophycocyanins 342 (650-655 nm) (Kannaujiya and Sinha 2015). Plocamium species possess chlorophyll a, and the 343 presence of phycobiliproteins is important to capture light of various wavelengths, allowing for 344 more efficient photosynthesis (Govindjee and Braun 1974). Furthermore, the composition of 345 photosynthetic pigments in seaweeds varies according to environmental parameters (Bryant 346 1982).

The first collection site of $P$. brasiliense (P1) is a subtidal environment, and specimens

348 were collected at a depth of $10 \mathrm{~m}$ and water temperature of $13^{\circ} \mathrm{C}$; these conditions may account 349 for the physiologic mechanisms that allow this seaweed to adapt to varying light conditions. 350 Specimens of $P$. brasiliense collected from the second site (P2) also express phycobiliprotein 351 complex proteins but at a lower level. Previous studies showed that these are upregulated in the 
352 environmental conditions of higher temperature and desiccation (López-Cristoffanini et al.

353 2015), which may explain the expression of allophycocyanin in P. brasiliense specimens from

354 P2, which were exposed to extreme sunlight and desiccation. Regarding the other two

355 phycobiliproteins, phycoerythrin and phycocyanin, we suggest that they are found in higher

356 numbers in P1 because shorter light wavelengths reach deeper depths than longer light

357 wavelenghts. The majority of proteins expressed in P2 were previously reported as stress

358 response proteins: $\mathrm{CbbX}$ and Elongation Factor on nitrogen stress-response in the red algae

359 Gracilaria gracilis (Naidoo et al. 2016), ATP synthase on light stress-response in the seagrass

360 Zostera muelleri (Kumar et al. 2017) and Haloalkanedehalogenase on pollution stress-response

361 (Buryska et al. 2018). These proteins are likely to be involved in stress-response in $\mathrm{P} 2$

362 individuals since this population is in a region with higher temperatures compared with $\mathrm{P} 1$, and

363 is routinely under desiccation stress.

364 Although the protein profile was obtained from 1D semi-quantitative method, we 365 analyzed specimens exposed to distinct abiotic conditions (in situ). This way our study brings 366 new information on the proteome of Rhodophyta class, which until this study were restricted to 367 controlled experiments in laboratories (Wong et al. 2006, López-Cristoffanini et al. 2015, 368 Naidoo et al. 2016, Xu et al. 2016). Further this is a first attempt to uncover the proteomic 369 diversity of the genus Plocamium.

3705 Conclusion

Protein content of two populations of $P$. brasiliense that are nearly identical genetically is

372 modulated by environmental conditions. The high phenotypic plasticity of this red seaweed

373 allows it to occupy contrasting ecological niches, from sites of upwelling to intertidal zones. The

374 differential proteomic profiles of these two populations are consistent with findings of previous 
375 studies, which reported differences in secondary metabolite profiles of distinct populations of $P$.

376 brasiliense. This study is a first attempt to study the metaproteome of the $P$. brasiliense

377 holobiont to determine how nearly identical populations cope with changing environmental

378 conditions. In our study, light availability appeared to influence the production of 379 phycobiliprotein (light-harvesting antennae). 
381

382

383

384

385

386

387

388

389

390

391

392

393

394

395

396

397

398

399

400

401

402

403

\section{References}

Alves, C., Pinteus, S., Rodrigues, A., Horta, A. \& Pedrosa, R. 2018. Algae from Portuguese Coast Presented High Cytotoxicity and Antiproliferative Effects on an in vitro Model of Human Colorectal Cancer. Pharmacognosy Res. 10:24-30.

Benson, D.A., Cavanaugh, M., Clark, K., Karsch-mizrachi, I., Lipman, D.J., Ostell, J. \& Sayers, E.W. 2017. GenBank. Nucleic Acids Res. 45:D37-42.

Bouza, N., Caujapé-Castells, J., Gonzáles-Pérez, M.Á. \& Sosa, P.A. 2006. Genetic Structure of Natural Population in the Red Algae Gelidium canariense (Gelidiales, Rhodophyta) Investigated by Random Amplified Polymorphic DNA (RAPD) Markers. J. Phycol. $42: 304-11$.

Bryant, D.A. 1982. Phycoerythrocyanin and Phycoerythrin: Properties and Occurrence in Cyanobacteria. Microbiology. 128:835-44.

Buryska, T., Babkova, P., Vavra, O., Damborsky, J. \& Prokop, Z. 2018. A Haloalkane Dehalogenase from a Marine Microbial Consortium Possessing Exceptionally Broad Substrate Specificit. Appl. Environ. Microbiol. 84:e01684-17.

Carson, M.A. \& Clarke, S.A. 2018. Bioactive compounds from marine organisms: Potential for bone growth and healing. Mar. Drugs. 16.

Claudino, M.M., Domingos, T.F.S., da Silva, G.A., Fonseca, R.R., Cavalcanti, D.N., Sanchez, E.F., Teixeira, V.L., Fuly, A.L. 2014. Inhibitory effect of the red seaweed Plocamium brasiliense against the toxic effects of Lachesis muta snake venom. J. Appl. Phycol. 26:2047-54.

Coelho, A., Santos, E.O., Faria, M.L., Carvalho, D.P., Soares, M.R., von Kruger, W.M. \& Bisch, P.M. 2004. A proteome reference map for Vibrio cholerae El Tor. Proteomics. 4:1491-504. 
404 Contreras-Porcia, L. \& López-Cristoffanini, C. 2012. Proteomics in Seaweeds: Ecological 405 Interpretations. In Gel Electrophoresis - Advanced Techniques. InTech, pp. 21-52.

406 Cremades, J., Barreiro, R., Maneiro, I. \& Saunders, G.W. 2011. A new taxonomic interpretation 407 of the type of Plocamium cartilagineum (Plocamiales, Florideophyceae) and its 408 consequences. Eur. J. Phycol. 46:125-42.

409 de Oliveira, L.S., Tschoeke, D.A., S, de O.A., Hill, L.J., Paradas, W.C., Salgado, L.T., 410 Thompson, C.C., Pereira, R.C., Thompson, F.L. 2015. New Insights on the Terpenome of 411 412 13:879-902.

413

Edgar, R.C. 2004. MUSCLE: A Multiple Sequence Alignment Method With Reduced Time and 415 Space Complexity. BMC Bionformatics. 5:1-19.

Faugeron, S., Martı, E.A., Correa, J.A. \& Cardenas, L. 2004. Reduced Genetic Diversity and Increased Population Differentiation in Peripheral and Overharversted Populations of Gigartina skottsbergii (Rhodophyta, Gigartinales) in Southern Chile. J. Phycol. 462:454418 62.

419 Garcia, G.D., Santos, E.O., Sousa, G. V, Zingali, R., Thompson, C.C. \& Thomson, F.L. 2016. 420 Metaproteomics reveals metabolic transitions between healthy and diseased stony coral. $421 \quad$ Mol. Ecol. 25:4632-44.

422 Gerloff-Elias, A., Barua, D., Mölich, A. \& Spijkerman, E. 2018. Temperature- and pH423 dependent accumulation of the heat-shock proteins in the acidophilic green alga 424 Chlamydomonas acidophila. FEMS Microb. Ecol. 56:345-54.

425 Getachew, P., Hannan, A., Nam, B.-H., Cho, J.-Y. \& Hong, Y.-K. 2014. Induced changes in the 426 proteomic profile of the phaeophyte Saccharina japonica upon colonization by the 
bryozoan Membranipora membranacea. J. Appl. Phycol. 26:657-64.

428 Getachew, P., Nam, B., Cho, J.Y. \& Hong, Y. 2016. Influences of hydrozoan colonization on 429 proteomic profiles of the brown alga Saccharina japonica. Bot. Mar. 59:85-93.

430 Gouy, M., Guindon, S. \& Gascuel, O. 2010. SeaView Version 4: A Multiplatform Graphical 431 User Interface for Sequence Alignment and Phylogenetic Tree Building. Mol. Biol. Evol. $432 \quad 27: 221-4$.

433 Govindjee \& Braun, B.Z. 1974. Light Absorption, Emission and Photosynthesis. In Stewart, W. 434 435 D. P. [Ed.] Algal Physiology and Biochemistry. pp. 346-90.

35 Guenther, M., Gonzalez-Rodriguez, E., Carvalho, W.F., Rezende, C.E., Mugrabe, G. \& Valentin, 438 Guiry, M.D. \& Guiry, G.M. 2016. AlgaeBase.

439 Harley, C.D.G., Anderson, K.M., Demes, K.W., Jorve, J.P., Kordas, R.L., Coyle, T.A. \& 440 Graham, M.H. 2012. Effects of Climate Change on Global Seaweed Communities. J. 441 Phycol. 48:1064-78.

442 Hartl, F.U. 1996. Molecular chaperones in cellular protein folding. Nature. 381:571-80.

443 Hu, Y., Sui, Z., Zhou, W., Wang, J., Chang, L., Guo, W. \& Li, B. 2018. Development of 444 genomic simple sequence repeat markers and genetic diversity analysis of Gracilariopsis 445 lemaneiformis (Rhodophyta). J. Appl. Phycol. 30:707-16.

446 Kannaujiya, V.K. \& Sinha, R.P. 2015. Thermokinetic stability of phycocyanin and phycoerythrin 447 in food-grade preservatives. J. Appl Phycol. 28:1063-70.

448 Kumar, M., Padula, M.P., Davey, P., Pernice, M., Jiang, Z., Sablok, G., Contreras-Porcia, L., 449 Ralph, P.J. 2017. Proteome Analysis Reveals Extensive Light Stress-Response 
Reprogramming in the Seagrass Zostera muelleri (Alismatales, Zosteraceae) Metabolism.

451 Front. Plant Sci. 7:1-19.

452 Kumar, S., Stecher, G. \& Tamura, K. 2016. MEGA7: Molecular Evolutionary Genetics Analysis 453 Version 7.0 for Bigger Datasets. Mol. Biol. Evol. 33:1870-4.

454 Laemmli, U.K. 1970. Cleavage of structural proteins during the assembly of the head of $455 \quad$ bacteriophage T4. Nature. 227:680-5.

456 Lemasson, C., de Marsac, N.T. \& Cohen-Bazire, G. 1973. Role of Allophycocyanin as a Light457 Harvesting Pigment in Cyanobacteria. PNAS. 70:3130-3.

458 Lin, S.-M., Fredericq, S. \& Hommersand, M.H. 2001. Systematics of the Delesseriaceae 459 (Ceramiales, Rhodophyta) Based on Large Subunit rDNA and rbcL Sequences, Including 460 the Phycodryoideae, Subfam. Nov. J. Phycol. 37:881-99.

461 López-Cristoffanini, C., Zapata, J., Gaillard, F., Potin, P., Correa, J.A. \& Contreras-Porcia, L. 462 2015. Identification of proteins involved in desiccation tolerance in the red seaweed 463 Pyropia orbicularis (Rhodophyta, Bangiales). Proteomics. 15:3954-68.

464 Naidoo, R.K., Rafudeen, M.S. \& Coyne, V.E. 2016. Investigation of the Gracilaria gracilis 465 (GLACILARIALES, RHODOPHYTA) Proteome Response to Nitrogen Limitation. $J$. $466 \quad$ Phycol. 52:369-83.

467 Nei, M. 1973. Analysis of Gene Diversity in Subdivided Populations. Proc. Natl. Acad. Sci. $468 \quad$ United States Am. 70:3321-3.

469 Pereira, R. \& Vasconcelos, M. 2014. Chemical defense in the red seaweed Plocamium 470 brasiliense: spatial variability and differential action on herbivores. Brazilian J. Biol. $471 \quad 74: 545-52$.

472 Pereira, R.C. \& Costa-Lotufo, L. V 2012. Bioprospecting for bioactives from seaweeds: 
potential, obstacles and alternatives. Rev Bras Pharmacog. 22:894-905.

474 Raines, C.A. 2011. Increasing Photosynthetic Carbon Assimilation in C3 Plants to Improve Crop 475 Yield: Current and Future Strategies. Plant Physiol. 155:36-42.

476 Santelices, B. 1990. Patterns of Reprodruction, Dispersal and Recruitment in Seaweed. 477 Oceanogr. Mar. Biol. - An Annu. Rev. 28:177-276.

478 Saunders, G.W. \& Lehmkuhl, K.V. 2005. Molecular divergence and morphological diversity 479 among four cryptic species of Plocamium (Plocamiales, Florideophyceae) in northern 480 Europe. Eur. J. Phycol. 40:293-312.

481

482

483

484

485

486

487

488

489

490

491

492

493

494

495

Sherwood, A., Sauvage, T., Kurihara, A., Conklin, K.Y. \& Presting, G.G. 2010. A comparative analysis of COI, LSU and UPA marker data for the Hawaiian florideophyte Rhodophyta: implications for DNA barcoding of red algae. Cryptogam. Alogologie. 31:451-65.

Sherwood, A.R. \& Presting, G.G. 2007. Universal Primers Amplify a 23S rDNA Plastid Marker in Eukaryotic Algae and Cyanobacteria. J. Phycol. 43:605-8.

Sinha, R.P. \& Häder, D.-P. 2003. Biochemistry of phycobilisome disassembly by ultraviolet-B radiation in cyanobacteria. Recent Res. Devel. Biochem. 4:945-55.

Stamatakis, A. 2014. RAxML version 8: A Tool for Phylogenetic Analysis and Post-Analysis of Large Phylogenies. Bioinformatics. 30:1312-3.

Tâmega, F.T.S. \& Figueiredo, M.A.O. 2005. Distribuição das Algas Calcárias Incrustantes (Corallinales, Rhodophyta) em Diferentes Habitats na Praia do Forno, Armação dos Búzios, Rio de Janeiro. Rodriguésia. 57:123-32.

Tan, P.L., Lim, P.E., Lin, S.M., Phang, S.M., Draisma, S.G.A. \& Liao, L.M. 2018. A genetic diversity assessment of Halymenia malaysiana (Halymeniaceae, Rhodophyta) from Malaysia and the Philippines based on COI-5P and rbcL sequences. J. Appl. Phycol. 1-10. 
496 Tatarenkov, A., Kautsky, L., Jo, R.B. \& Kautsky, L. 2007. Genetic structure in populations of 497 Fucus vesiculosus (Phaeophyceae) over spatial scales from $10 \mathrm{~m}$ to $800 \mathrm{~km}$. J. Phycol. $498 \quad 43: 675-85$.

499 R Core Team. 2017. R: A Language and Environment for Statistical Computing. Vienna, $500 \quad$ Austria.

501 Tee, M.Z., Yong, Y.S., Rodrigues, K.F. \& Yong, W.T.L. 2015. Growth rate analysis and protein 502 identification of Kappaphycus alvarezii ( Rhodophyta , Gigartinales ) under pH induced $503 \quad$ stress culture. Aquac. Reports. 2:112-6.

504 Wong, P.F., Tan, L.J., Nawi, H. \& AbuBakar, S. 2006. Proteomics of the red alga, Gracilaria 505 changii (Gracilariales, Rhodophyta). J. Phycol. 42:113-20.

506 Wright, J.T., Zuccarello, G.C. \& Steinberg, P. 2000. Genetic Structure of the Subtidal Red Alga 507 Delisea pulchra. Mar. Biol. 136:439-48.

508 Xu, K., Xu, Y., Ji, D., Xie, J., Chen, C. \& Xie, C. 2016. Proteomic analysis of the economic 509 seaweed Pyropia haitanensis in response to desiccation. Algal Res. 19:198-206.

510 Yang, E.C., Kim, M.S., Geraldino, P.J.L., Sahoo, D., Shin, J.A. \& Boo, S.M. 2008. 511 Mitochondrial cox1 and plastid rbcL genes of Gracilaria vermiculophylla (Gracilariaceae, 512 Rhodophyta). J. Appl. Phycol. 20:161-8.

513 Yoneshigue, Y. 1985. Taxonomie et ecologie des algues marines dans la region de Cabo Frio 514 (Rio de Janeiro, Bresil). Université d' Aix-Marseille, 466 pp.

515 Yotsukura, N., Nagai, K., Kimura, H. \& Morimoto, K. 2010. Seasonal changes in proteomic 516 profiles of Japanese kelp: Saccharina japonica (Laminariales, Phaeophyceae). J. Appl. $517 \quad$ Phycol. 22:443-51.

518 Yotsukura, N., Nagai, K., Tanaka, T., Kimura, H. \& Morimoto, K. 2012. Temperature stress- 
519 induced changes in the proteomic profiles of Ecklonia cava (Laminariales, Phaeophyceae).

$520 \quad$ J. Appl. Phycol. 24:163-71.

521 


\section{Figure 1 (on next page)}

ML tree from all COX1 Plocamium available at GenBank plus new sequences. All groups $>$ two individuals had a high bootstrap value. It is possible to note different groups composed by the "same species". 


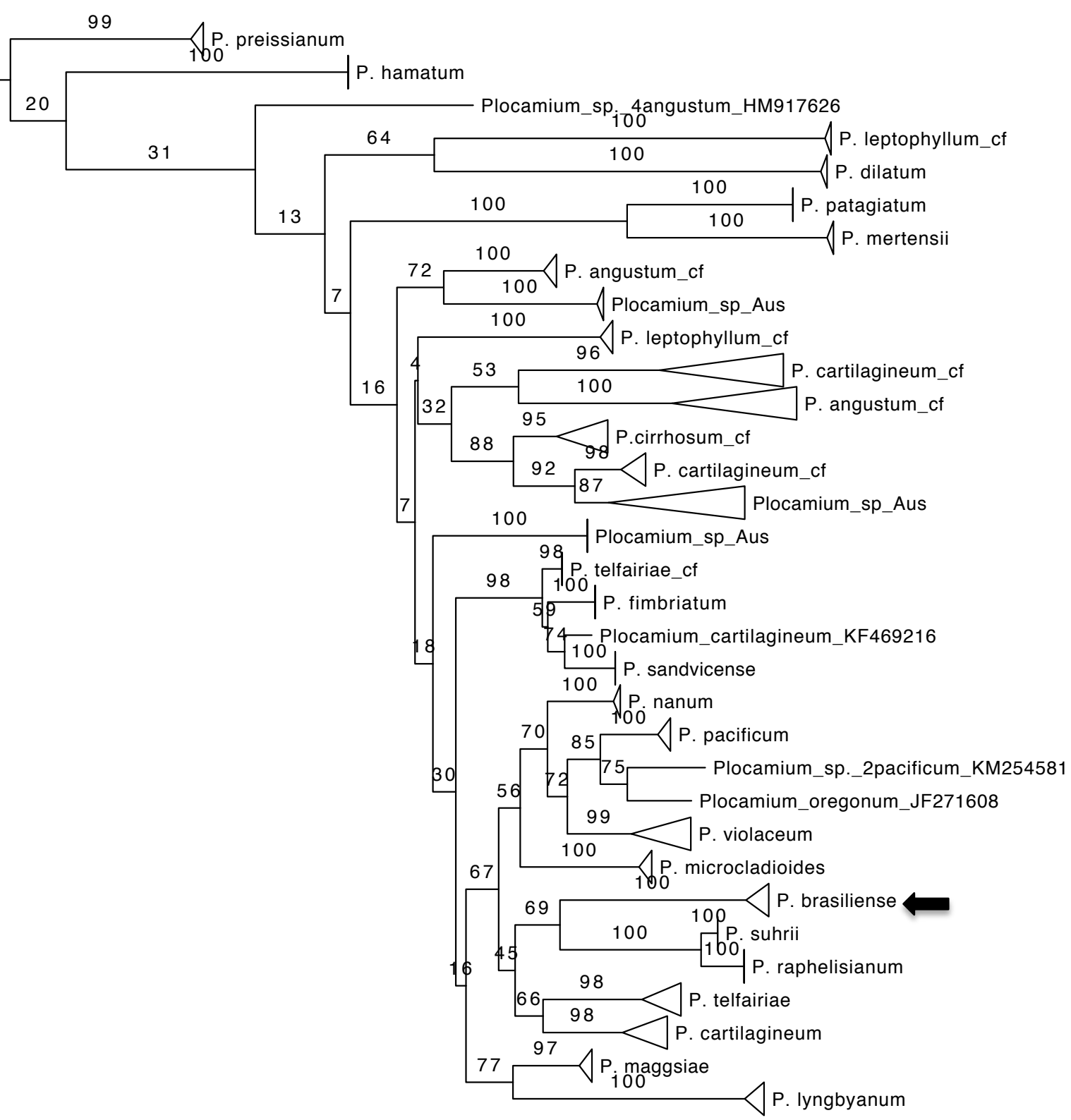




\section{Figure 2 (on next page)}

Maximum likelihood phylogenetic tree for the concatenated dataset (individual level) showing the relationship of five Plocamium species. In this tree we did not observe a structure between the two populations of $P$. brasiliense. 


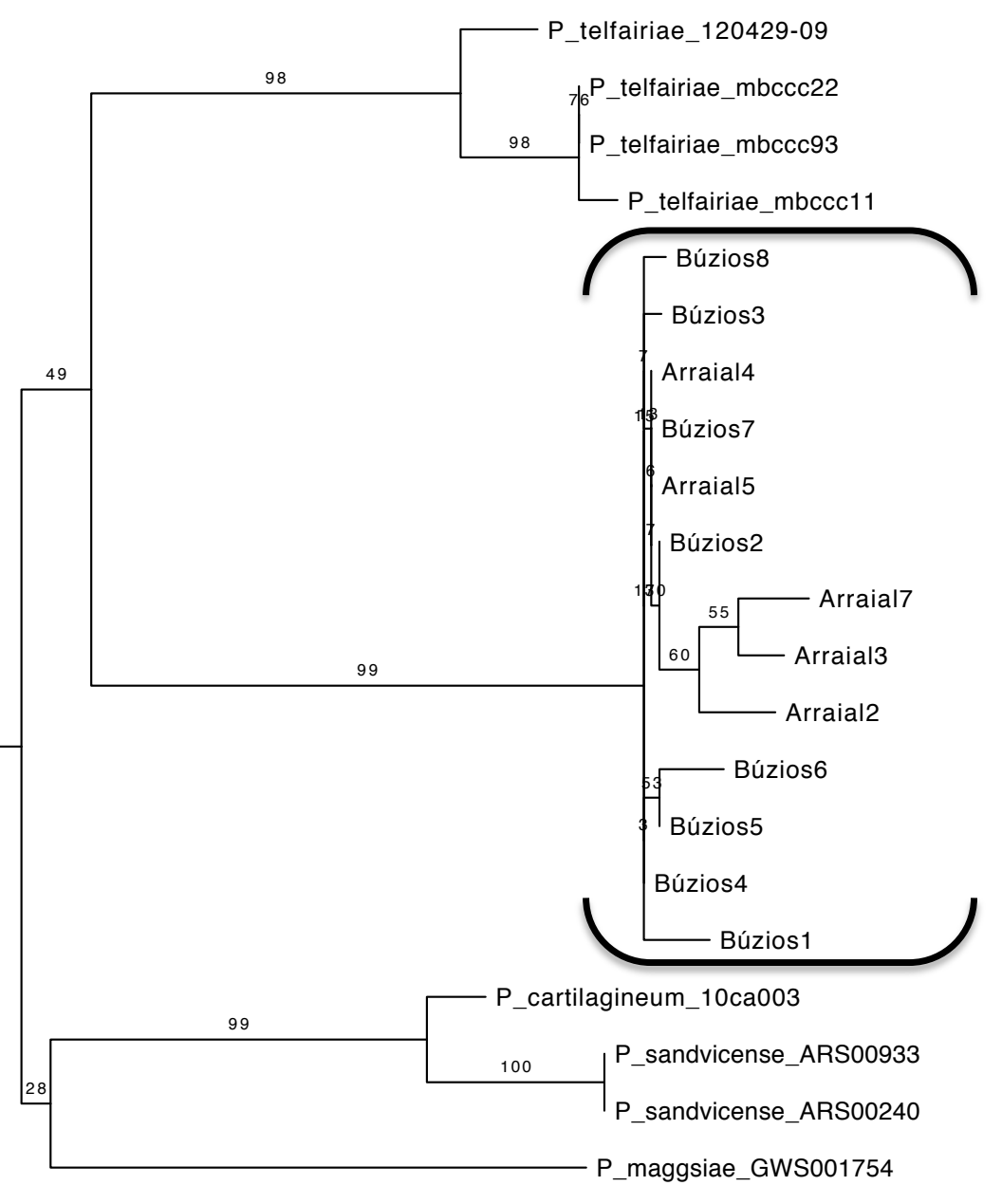

L_majuscula_ARS00686 


\section{Table $\mathbf{1}$ (on next page)}

Proteins of $P$. brasiliense individuals sampled in two distinct locations at Rio de Janeiro state. The values are given in percentage and the total number (within parenthesis); ${ }^{*}$ ) abundance significantly distinct between sites. 
1 Table 1. Proteins of $P$. brasiliense individuals sampled in two distinct locations at Rio de Janeiro state, Brazil (Arraial do Cabo: $13 \mathrm{~m}$ of deep and water temperature $13^{\circ} \mathrm{C}$, Búzios: $2 \mathrm{~m}$ of deep and water temperature of $18^{\circ} \mathrm{C}$. The values are given in total number and the percentage (within parenthesis); $\left(^{*}\right)$ abundance significantly distinct between sites

\begin{tabular}{llll}
\hline Protein & Arraial & Búzios & Total \\
\hline 14-3-3 protein & $1(0.12)$ & $2(0.48)$ & $3(0.24)$ \\
40S ribosomal protein S4 & $3(0.37)$ & $0(0.00)$ & $3(0.24)$ \\
Allophycocyanin* & $96(11.76)$ & $68(16.39)$ & $164(13.32)$ \\
ATP synthase* & $48(5.88)$ & $54(13.01)$ & $102(8.29)$ \\
ATPase & $13(1.59)$ & $8(1.93)$ & $21(1.71)$ \\
CbbX* & $0(0.00)$ & $4(0.96)$ & $4(0.32)$ \\
CfxQ & $3(0.37)$ & $2(0.48)$ & $5(0.41)$ \\
Collagen & $3(0.37)$ & $0(0.00)$ & $3(0.24)$ \\
Elongation factor* & $3(0.37)$ & $8(1.93)$ & $11(0.89)$ \\
Fructose-1,6-bisphosphatase & $5(0.61)$ & $2(0.48)$ & $7(0.57)$ \\
Glyceraldehyde-3-phosphate dehydrogenase & $9(1.10)$ & $10(2.41)$ & $19(1.54)$ \\
Haloalkane dehalogenase* & $0(0.00)$ & $6(1.45)$ & $6(0.49)$ \\
Heat shock protein 70* & $13(1.59)$ & $2(0.48)$ & $15(1.22)$ \\
Histone protein & $3(0.37)$ & $0(0.00)$ & $3(0.24)$ \\
Hypothetical protein* & $14(1.72)$ & $0(0.00)$ & $14(1.14)$ \\
Paramyosin & $6(0.74)$ & $0(0.00)$ & $6(0.49)$ \\
Phycobilisome & $2(0.25)$ & $2(0.48)$ & $4(0.32)$ \\
Phycocyanin* & $80(9.80)$ & $8(1.93)$ & $88(7.15)$ \\
Phycoerythrin & $235(28.80)$ & $104(25.06)$ & $339(27.54)$ \\
Plastid oxygen-evolving enhancer 1 & $4(0.49)$ & $4(0.96)$ & $8(0.65)$ \\
Ribulose-1,5-bisphosphate carboxylase & $257(31.50)$ & $126(30.36)$ & $383(31.11)$ \\
Sulfate adenylyltransferase & $3(0.37)$ & $0(0.00)$ & $3(0.24)$ \\
Translation elongation factor & $1(0.12)$ & $1(0.24)$ & $2(0.16)$ \\
Tropomyosin & $6(0.74)$ & $0(0.00)$ & $6(0.49)$ \\
Ubiquitin/actin fusion protein & $6(0.74)$ & $0(0.00)$ & $6(0.49)$ \\
Uncharacterized protein & $2(0.25)$ & $4(0.96)$ & $6(0.49)$ \\
\hline
\end{tabular}


